\title{
Yetişkinde Morgagni Hernilerinin Cerrahi Sonuçları
}

\section{Surgical Results of Morgagni Hernias in Adults}

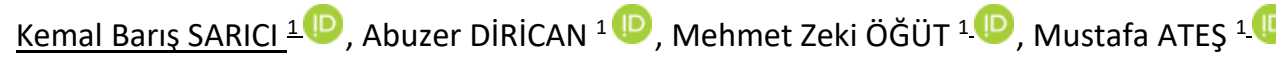 \\ 1 İnönü Üniversitesi Tıp Fakültesi, Genel Cerrahi Anabilim Dalı, Malatya, Türkiye
}

öz.

Amaç: Bu çalışmada yetişkinlerde çok sık görülmeyen Morgagni hernisi nedeniyle cerrahi tedavi yaptığımız hastalarımızın sonuçlarını sunmak amaçlanmışır.

Materyal ve Metod: Kliniğimizde Eylül 2009 ile Eylül 2020 tarihleri arasında Morgagni hernisi nedeniyle cerrahi tedavi uygulanan hastaların dosyaları geriye dönük incelendi. Hastaların demografik özellikleri ve cerrahi tedavi sonuçları kaydedildi. Hastalar laparoskopik ve açık cerrahi yapılan hasta grubu olarak ayrıldı. Gruplara İstatistik analizlerde Mann-Whitney U testi kullanıldı, $p<0,05$ değeri istatistiksel olarak anlamlı kabul edildi.

Bulgular: Cerrahi yapılan 6 hastanın 3'üne (\%50) açık cerrahi, 3'üne (\%50) laparoskopik cerrahi yapıldı. Hastaların hepsine (acil ameliyata alınan 1 hasta hariç) propropilen ve dual mesh uygulandı. Hastaların 2 'sinde (\%33) postoperatif komplikasyon (minimal pnömotoraks ve atelektazi) görüldü. Hasta grupları (açık ve laparoskopik) karşılatıldığında postoperatif hastanede kalış süreleri arasında istatistiksel olarak anlamlı bir fark vardı $(p<0,037)$.

Sonuç: Bu çalışma göstermiştir ki, Morgagni hernisi nadir görülen bir durumdur. Hastalar non spesifik semptomlarla başvururlar. Bunun yanında çeşitli cerrahi tekniklerle tedavisi mümkündür. Bunlar içinde laparoskopik cerrahi, hastanın hem ameliyat sonrası konforunu artırmakta, hem de hastanede kalış süresini kısaltmaktadır.

Anahtar kelimeler: Morgagni hernisi, Diyafram hernisi, Laparoskopik cerrah

\section{Abstract}

Background: In this study, we aimed to present the results of our patients who underwent surgical treatment for Morgagni hernia, which is not common in adults.

Materials and Methods: The files of patients who underwent surgical treatment for Morgagni Hernia in our clinic between September 2009 and September 2020 were retrospectively reviewed. Demographic characteristics of the patients and surgical treatment results were recorded. The patients were divided into patients who underwent laparoscopic and open surgery. Mann-Whitney $U$ test was used for statistical analysis of the groups, $\mathrm{p}<0.05$ value was considered statistically significant.

Results: Open surgery was performed in $3(50 \%)$ of 6 patients who underwent surgery, and laparoscopic surgery was performed in $3(50 \%)$ of them. Propropylene and dual mesh were applied to all patients (except 1 patient who was taken into emergency surgery). Postoperative complications (minimal pneumothorax and atelectasis) were observed in 2 (33\%) of the patients. When the patient groups (open and laparoscopic) were compared, there was a statistically significant difference between the postoperative hospital stay $(p<0.037)$.

Conclusions: This study showed that Morgagni hernia is a rare condition. Patients present with nonspecific symptoms. In addition, it can be treated with various surgical techniques. Among these, laparoscopic surgery both increases the comfort of the patient after surgery and shortens the duration of hospital stay.

Key Words: Morgagni hernia, Diaphragmatic hernia, Laparoscopic surgery

Corresponding Author/Sorumlu Yazar

Dr.Öğr.Üyesi Kemal Barış SARICI

İnönü Üniversitesi Tıp Fakültesi

Genel Cerrahi Anabilim Dalı

Malatya, Türkiye

E-mail: kemal.sarici@inonu.edu.tr

Received / Geliş Tarihi: 13.01.2021

Accepted / Kabul Tarihi: 08.04.2021

DOI: 10.35440/hutfd.860655 


\section{Giriş}

Solunum için temel görevi olan diyafram göğüs ve abdominal kaviteyi birbirinden ayıran kubbe şeklinde muskulotendinöz bir yapıdır. Diyafram, sternum, kosta ve lumbal vertabralara tutunur. (1).

Diyafram hernileri karın boşluğundaki organ veya yapıların diyaframdaki konjenital veya sonradan oluşan defektlerden toraks boşluğuna doğru yer değiştirmesidir. Konjenital diyafragma hernileri Bochdalek (sol postero-lateral \%95), Morgagni (anterior-retrosternal \%1.4) ve hiatal (hiatusda \%1) hernileridir (Şekil1) (2). Morgagni hernisi; retrosternal alanda lokalize Morgagni forameni diye tanımlanan septum trasversum ve diyafragmanın kostal kenarları arasındaki defektten intraabdominal organların, torakal kaviteye yer değiştirmesi sonucu oluşur (3).

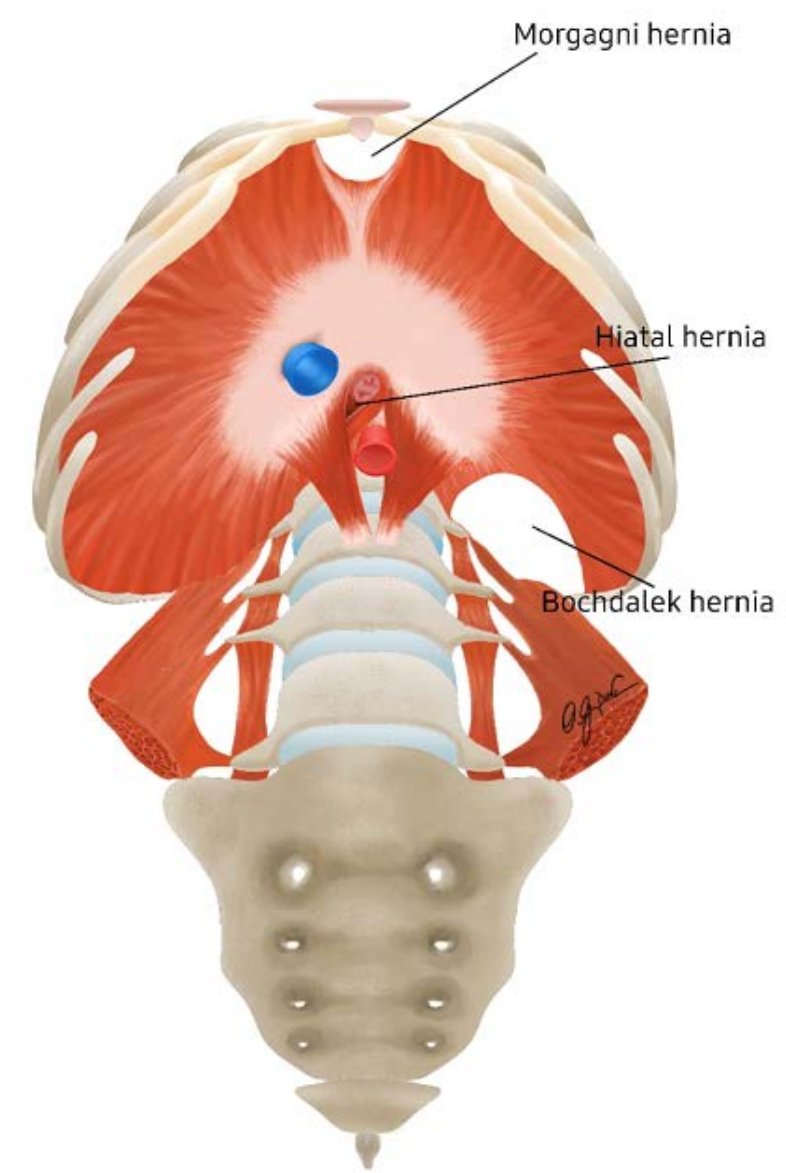

Şekil 1. Konjenital diyafram hernileri. Şekil 1, Dr. Orhan Gazi Dinç'in izniyle kullanılmıştır.

Morgagni hernilerinin tanısı radyolojik tetkiklerle konulur. Standart göğüs radyografisi fıtıklaşmış organa bağlı olarak, katı veya hava içeren; sağ, sol veya iki tarafıı perikardiyofrenik anormallikleri gösterir. Bilgisayarlı Tomografi taramaları tanısaldır. Çünkü oral kontrasta ihtiyaç duymadan retrosternal hernie olmuş omentum, yağ dokusu ve içi boş organları gösterir. Manyetik Rezonans da Bilgisayarlı Tomografiyle benzer bulguları verebilir, ancak genellikle ihtiyaç duyulmaz (3).
Bu çalışmada, yetişkinlerde çok sık rastlanmayan Morgagni hernileri konusunda ki, kliniğimizin cerrahi tecrübesini literatür eşliğinde sunmayı amaçladık.

\section{Materyal ve Metod}

Eylül 2009 ile Eylül 2020 tarihleri arasında Morgagni Hernisi nedeniyle kliniğimizde cerrahi tedavi uygulanan hastaların dosyaları çıkarılarak geriye dönük incelendi. ÇaIışma için etik kurul onayı İnönü Üniversitesi Tıp Fakültesi Sağlık Bilimleri Girişimsel Olmayan Klinik Araştırmalar Etik Kuru-lundan 27/10/2020 tarih ve 17.oturumunda 2020/1138 sayılı kararı ile alınmıştır. Hastaların yaş, cinsiyet, görüntüleme yöntemi, ek hastalık, başvuru şikayeti, diyaframdaki defektin lokalizasyonu ve boyutları, uygulanan cerrahi şekli (transabdominal yaklaşımla laparaskopik ve açık cerrahi), operasyon süresi, herniye olan organlar, hastanede yatış süresi, postoperatif komplikasyonlar ve cerrahi sonuçlar kayıt edildi.

Cerrahi yöntem olarak transabdominal yaklaşımla laparaskopik ve açık cerrahi yapıldı. Laparaskopik cerrahide kamera için standart 12'lik torokar kullanıldı. Diğer torakarlar ise cerrahın tercihine bağlı olarak 1 adet $10^{\prime}$ luk, 2 adet 5 'lik veya 3 adet 5 'lik olarak kullanıldı. Defekt onarımında non absorbable propropilen süturlar kullanıldı. Bazı hastalarda destek amaçlıda propropilen veya dual meshler kullanıldı. Meshler laparoskopik sabitleyici (tucker) ile defekt alanına tespit edildi. Polipropilen mesh üzeri falsiform ligaman veya omentum ile abdominal kavite tarafından örtüldü.

Açık cerrahide ise göbek üstü median (apendektomi de yapılan hastaya sağ lateral insizyon eklendi) insizyon tercih edildi. Defekt onarımında non absorbable propropilen süturlar kullanıldı. Gerektiğinde destek amaçlı olarak polipropilen ve dual meshler kullanıldı. Meshler propropilen süturlar ile defekt alanına tespit edildi. Polipropilen mesh üzeri falsiform ligaman veya omentum ile abdominal kavite tarafından örtüldü.

Hastalar laparoskpik ve açık cerrahi yapılan hasta gruplarına ayrıldı. Gruplar; yaş, ameliyat süresi ve hastanede kaIış süreleri açısından karşılaştırıldı. Veriler ortanca (minmaks) ve sayı (yüzde) ile verildi. İstatistik analizlerde Mann-Whitney U testi kullanıldı. $p<0,05$ değeri istatistiksel olarak anlamlı kabul edildi. Analizlerde IBM SPSS Statistics 25.0 programı kullanıldı.

\section{Bulgular}

Morgagni hernisi sebebiyle kliniğimizde 6 hastaya cerrahi uygulandı. hastaların 3' ü (\%50) erkek ,3’ ü (\%50) kadındı. Laparoskopik cerrahi yapılan hastaların yaşları 40-65 yıl arasında olup medyan 44 yıldı. Açık cerrahi yapılan hastaIarın yaşları 35-80 yıl arasında olup medyan 78 yıldı. Yapılan cerrahilerden 5'i (\%83) elektif cerrahi olup 1' i (\%17) gebelik sonrası solunum sıkıntısı nedeniyle acil cerrahiydi. Hastaların 3' ünde (\%50) ek hastalık (Diabetes Mellitus, Hipertansiyon, Konjestif Kalp Yetmezliğ, Gebelik) varken 3 
(\%50) hastada herhangi bir özellik yoktu. Hastaların ağırIıklı olarak hastaneye başvuru nedenleri karın ağrısıydı (6 hasta). Buna ek olarak nefes dalığı ( 2 hasta) ve ileus (1 hasta) şikayetleri olan hastalar da vardı. Hastaların tanılarında radyolojik tetkiklerden toraks ve/veya abdomen bilgisayarlı tomografi (BT)(Şekil 2), abdominal ultrasonografi (USG) ve posteroanterior akciğer (PAAC) grafisi kullanıldı (Tablo 1).

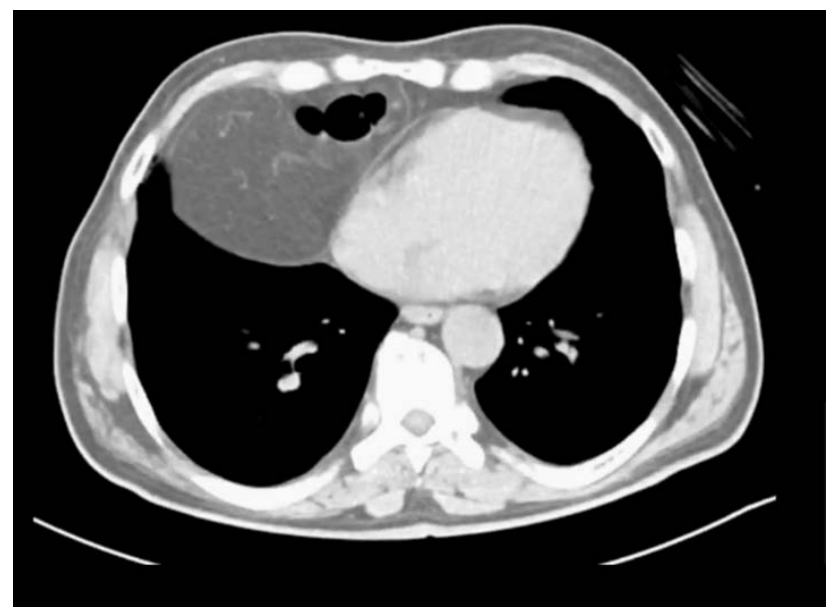

Şekil 2. Ameliyat öncesi BT görüntüsü

Cerrahi tedavi olarak 3 hastaya (\% 50) açık cerrahi, 3 hastaya (\% 50) laparaskopik cerrahi (Şekil 3) yapıldı. Ameliyat süreleri laparoskopik cerrahi yapılanlarda 90-180 dakika arasında, medyan 120 dakikaydı; açık cerrahi yapılanlarda 120-270 dakika arasında, medyan 120 dakikaydı. Bu cerrahilerde laparoskopik cerrahi yapılan 2 hastaya (\%67) primer kapama ve mesh uygulandı, 1 hastaya (\% 33) primer kapama yapılmadan sadece mesh kullanıldı. Açık cerrahi yapılan 2 hastaya (\%67) primer kapama ve mesh uygulandı 1 hastaya (\% 33) sadece mesh kullanılmadan primer kapama yapıldı. Toraksa herniye olan organlar, transvers kolon, mide, ince barsak ve omentum idi. Laparoskopik cerrahi yapılan 2 hastada(\% 67) dual mesh, 1 hastada (\%33) prolen mesh kullanıldı. Açık cerrahi yapılan 2 hastada (\% 67) prolen mesh kullanıldı, sadece primer kapama yapılan acil operasyona alınan 1 hastada ( \%33) mesh kullanılmadı. Laparoskopik cerrahi yapılan 3 hastada hastanede kalış süreleri 3'er gündü, median 3 gündü. Açık cerrahi yapılan hastaların operasyon sonrası hastanede kalış süreleri 3-25 gün arasında olup median 8 gündü. Açık cerrahi yapılan hastaların 2' sinde (\%67) post operatif komplikasyon (minimal pnömotoraks ve atelektazi) görüldü. Minimal pnömotorax olduğu için hastaya göğüs tüpü takılmadı. Çalışmamızdaki hiçbir hastaya torakotomi yapılmadı ve göğüs tüpü takılmadı. Diğer açık cerrahi yapılan hasta ve laparoskopik cerrahi yapılan tüm hastalar sorunsuz olarak taburcu edildiler (Tablo 2).

Hasta grupları (açık ve laparoskopik) karşılatıldığında postoperatif hastanede kalış süreleri arasında istatistiksel anlamlı bir fark vardı (Tablo 3).

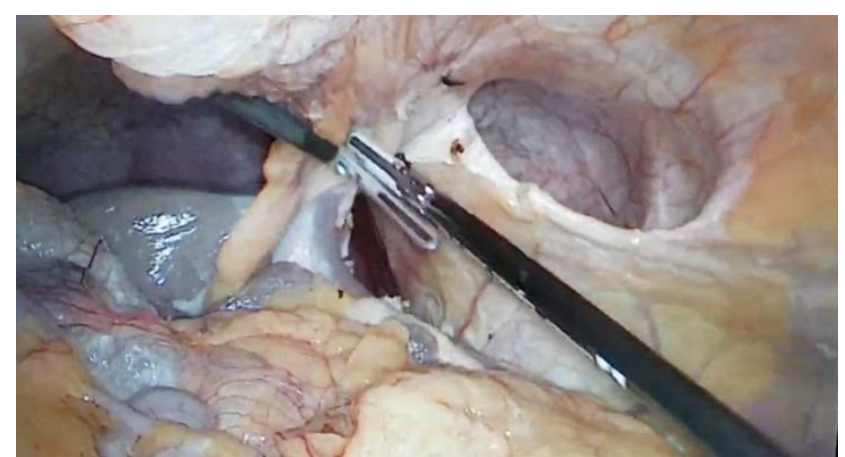

Şekil 3. Laparoskopik ameliyat görüntüsü (Morgagni hernisi)

\section{Tartışma}

Konjenital diyafram hernilerinden biri olan Morgagni hernileri genelde asemptomatiktir ve tesadüfen tanı konulur. Morgagni hernileri diyaframda anterior-retrosternal defektler olup \% 90 sağ tarafta, \% 8 sol tarafta ve \% 2 bilateral olarak görülür (4). Bizim çalışmamızda da 5 hastada (\%83) sağ tarafta 1 hastada (\%17) sol taraflı herni mevcuttu. Bu durum literatürle uyumlu olarak gözükmektedir. Hiç bilateral hernisi olan hastamız olmadı. Sağ tarafta karaciğer olmasına rağmen sağ tarafta herninin daha sık olması, sol tarafta kalp gibi daha hayati organları korumak için diyaframın daha sağlam liflerden oluştuğunu düşündürmektedir.

Morgagni herni kesesi içinde omentum, ince barsak ansları, kolon segmenti ve karaciğer olabilir. Bir çalışmada, en sık herniye olan organın transvers kolon olduğu belirtilmiştir. Herni kesesinde intestinal içeriğin saptanması ile tanının radyolojik olarak kolayca konabileceği belirtilmiştir (5). Hastalar asemptomatik olabilecekleri gibi nefes darlığı, öksürük, karın ağrısı, bulantı ve kusma gibi semptomlar da gösterebilirler (6). Semptomlar fıtık kesesinin içindeki organların çeşitliliğine göre şekillenir. Fıtık kesesine omentum, kolon girdiğinde karın ağrısı, bulantı ve kusma, mide girdiğinde dispeptik şikâyetler oluşabilir. Yine fıtık kesesinin büyüklüğüne bağlı olarak toraks boşluğunun kapasitesini azaltarak akciğerlere bası yapması sonucu dispne ve öksürük gelişebilir. Çalışmamızdaki hastalarda ağırlıklı semptom karın ağrısıydı. Tüm hastalarda karın ağrısı mevcuttu ve 2(\%33) hastada karın ağrısına ek olarak nefes darlığı da bulunuyordu.

Toraks ve abdominal BT, abdominal ultrasonografi, kontrast içirilerek çekilen abdominal grafiler tanıda yardımcı radyolojik tetkiklerdir. Ayrıca torakoskopi ve laparoskopi de tanıda tanısal modaliteler olabilirler(7). Çok kesitli BT'de koronal ve sagital görüntüler diyaframdaki defekti ve fıtık içeriğini ortaya koyabilen invaziv olmayan değerli tanı yöntemidir(8). Biz çalışamamızda ki 5(\%83) hastamıza toraks veya abdomen BT ile tanı koyduk. Sadece 1(\%17) hastamıza gebe olmasından dolayı BT çekemedik, abdomen USG yaptık. 
Tablo 1. Hastaların demografik özellikleri

\begin{tabular}{|c|c|c|c|c|c|c|c|c|}
\hline & $\begin{array}{l}\text { Yaş } \\
\text { (yıl) }\end{array}$ & Cinsiyet & Semptomlar & Teşhis & Ek hastalık & Başvuru & $\begin{array}{l}\text { Defekt } \\
\text { Tarafı }\end{array}$ & $\begin{array}{l}\text { Defekt } \\
\text { Büyüklüğü } \\
\text { (milimetre) }\end{array}$ \\
\hline 1 & 40 & Erkek & Nefes darlığı+Karın ağrısı & Torax BT & & Elektif & Sağ & $50 \times 50$ \\
\hline 2 & 65 & Erkek & Karın ağrısı & Abdomen BT & Diyabetes Mellitüs & Elektif & Sağ & $30 \times 30$ \\
\hline 3 & 78 & Kadın & Karın ağrısı & Torax BT & $\begin{array}{l}\text { Kalp yetmezliği+ } \\
\text { Hipertansiyon }\end{array}$ & Elektif & Sağ & $30 \times 30$ \\
\hline 4 & 80 & Kadın & Karın ağrısı & Torax BT & & Elektif & Sağ & $50 \times 50$ \\
\hline 5 & 44 & Erkek & Karın ağrısı & Abdomen BT & & Elektif & Sol & \\
\hline 6 & 35 & Kadın & Karın ağrısı+Nefes darlığı & Abdomen USG & Gebelik & Acil & Sağ & $100 \times 40$ \\
\hline
\end{tabular}

BT: bilgisayarlı tomografi, USG: ultrasonografi

Tablo 2. Hastaların cerrahi tedavileri ve sonuçları

\begin{tabular}{|c|c|c|c|c|c|c|c|c|}
\hline $\begin{array}{l}\text { Hasta } \\
\text { No }\end{array}$ & $\begin{array}{l}\text { Operasyon } \\
\text { Türü }\end{array}$ & $\begin{array}{l}\text { Cerrahi } \\
\text { Metod }\end{array}$ & Mesh & $\begin{array}{l}\text { Operasyon } \\
\text { Süresi } \\
\text { (dakika) }\end{array}$ & $\begin{array}{l}\text { Fıtık Kesesi } \\
\text { İçeriği }\end{array}$ & $\begin{array}{l}\text { Postoperatif } \\
\text { Komplikasyonlar }\end{array}$ & $\begin{array}{l}\text { Hastanede } \\
\text { Yatış Sü- } \\
\text { resi(gün) }\end{array}$ & Sonuç \\
\hline 1 & Laparoskopik & PK+Mesh & Dual & 120 & TK+Omentum & & 3 & Yaşıyor \\
\hline 2 & Laparoskopik & PK+Mesh & Prolen & 180 & Omentum & & 3 & Yaşıyor \\
\hline 3 & Açık & PK+Mesh & Prolen & 120 & TK+Omentum+Mide & Pnömotoraks & 25 & Yaşıyor \\
\hline 4 & Açık & PK+Mesh & Prolen & 120 & TK & Atelektazi & 6 & Yaşıyor \\
\hline 5 & Laparoskopik & Mesh & Dual & 90 & Omentum & & 3 & Yaşıyor \\
\hline 6 & Açık & PK & & 270 & $\mathrm{TK}+\mathrm{iB}$ & & 8 & Yaşıyor \\
\hline
\end{tabular}

iB: ince barsak

PK: primer kapama

Tk: transvers kolon

Tablo 3: Laparoskopik ve açık cerrahi yapılan hasta gruplarının karşılaştırılması

\begin{tabular}{|c|c|c|c|}
\hline \multirow{3}{*}{ Değişkenler } & \multicolumn{2}{|c|}{ Ameliyat Türü } & \multirow{3}{*}{ P* değeri } \\
\hline & Laparoskopik & Açık & \\
\hline & Median (min-max) & Median (min-max) & \\
\hline Yaş(yıl) & $44(40-65)$ & $78(35-80)$ & 0,487 \\
\hline Ameliyat süresi (dk) & $120(90-180)$ & $120(120-270)$ & 0,523 \\
\hline Hastanede yatış süresi (gün) & $3(3-3)$ & $8(6-25)$ & $0,037 *$ \\
\hline
\end{tabular}

* Mann Whitney $U$ test

Ameliyat endikasyonu hastanın şikayetlerine bağlıdır. Fıtıkların çoğu asemptomatiktir. Cerrahi daha çok ilerideki komplikasyonları önlemeye yöneliktir. Fıtık kesesi içine sıkışan bir kolonun obstrüksiyon yaratması yüksek risktir. Yine küçük bir fıtık kesesi içine giren omentum hastada tekrarlayan karın ağrılarına neden olursa cerrahi düşünülebilir( 9).

Morgagni herni onarımı laparotomi, laparoskopi, torakotomi veya torakoskopiyle yapılabilir (10). Biz hastalarımıza transabdominal yaklaşımları tercih ettik. Hastalarımızın $3(\% 50)^{\prime}$ üne açık cerrahi, 3(\%50)' üne ise laparaskopik cerrahi uyguladık. İster açık cerrahi isterse laporaskopik cerrahi yapılsın, cerrahi sırasında fıtık kesesini eksize etmek hakkında hala bir fikir birliği oluşmamıştır (11). Rau ve arkadaşları, postoperatif kist ve lobüllerin mediastinal seroma oluşumuna yol açacağını ve bu yüzden de fıtık kesesini eksize etmeyi önermişlerdir (12). Yine Ramanchandran ve arkadaşları serilerinde fıtık keselerini eksize etmediklerini ve post operatif sorun yaşamadıklarını bildirmişlerdir (13). Bizde hastalarmızın 2(\%33)' sinin fıtık kesesi eksize edildi, 4(\%67) hastanın fıtık kesesi eksize edilmedi. Hiçbir hastada postoperatif mediastinal sıvı ve nüks gibi bir sorun yaşamadık. Özellikle fıtık kesesinin yapıştığı hayati organlar (perikard gibi) fitık kesesini eksize ederken zarar görebilir.

Fıtık doğrudan kapatılabileceği gibi daha dayanıklı olması için non absorbable mesh (polypropilen gibi) ile kapatılabilir. Bu meshler intracorporeal sütur veya sabitleyiciler (tucker) ile sabitlenebilir (14). Bizde tüm hastalarımızda mesh (polypropilen veya dual) kullandık. Dual meshin kullanılmadığı durumlarda tespit edildikten sonra meşin karın boşluğuna bakan yüzü intestinle temas etmemesi için falsiform ligaman veya omentumla kapatıldı. Ancak primer kapamanın yapılamayacağı kadar büyük defektlerde dual meshi tercih ettik.

Morgagni hernilerinin cerrahi sonrası nüks oranları düşüktür. Jhon D ve arkadaşlarının yaptığı 298 vakalık derlemede 12 ile 85 aylık takiplerde 1 hastada nüks olduğu belirtilmiştir(10). Bizimde en uzun takip süresi 125 ay olan hastamızda nüks görülmedi. Aynı çalışmada laparoskopik yaklaşımın diğer yöntemlere göre mükemmel olduğunu vurgulanmıştır. Bizim çalışmamızda laparoskopik cerrahi uyguladığımız hastalarda postoperatif hastanede kalış süreleri daha kısa idi ve bu hastalarda hiçbir komplikasyon 
olmadı.

Çalışamamızda istatistiksel olarak sadece hastalarımızın cerrahi sonrası hastanede yatış süreleri anlamlı bulundu $(p=0,037)$. Çalışmamızın kısıtlılığı hasta sayımızın az olmasıdır. Belki daha büyük hasta serilerinin olduğu çalışmalarda başka parametrelerinde istatistiksel olarak anlamlı olacağı kanısındayız.

Sonuç olarak, nadir görülen klinik bir durum olan Morgagni hernili hastalar genellikle non spesifik karın ağrısı, dispeptik şikayetler ve dispne ile hekime başvururlar. Farklı cerrahi yaklaşımlarla etkili ve güvenli onarım mümkün olmakla beraber, laparaskopik cerrahi; hem hastanın postoperatif konforu, hemde hastanede daha kısa kalma süresi nedeniyle tercih edilebilir.

Etik onam: : Çalışma için etik kurul onayı Inönü Üniversitesi Tıp Fakültesi Sağlık Bilimleri Girişimsel Olmayan Klinik Araştırmalar Etik Kurulundan 27/10/2020 tarih ve 17.oturumunda 2020/1138 sayılı kararı ile alınmıştır.

\section{Yazar Katkıları}

Konsept: K.B.S., A.D.

Literatür Tarama: K.B.S., A.D.

Tasarım: M.A., A.D.

Veri toplama: K.B.S., M.Z.Ö.

Veri analizi ve yorumlama: K.B.S., A.D.

Makale yazımı: K.B.S., A.D.

içeriğin eleştirel incelenmesi: K.B.S., A.D., M.A.

Çıkar Çatışması: Yazarlar çıkar çatışması bildirmemişlerdir.

Finansal Destek: Çalışmamızda herhangi bir finansal kaynak kullanılmamıştır.

\section{Kaynaklar}

1. Sanford Z, Weltz AS, Brown J, Shockcor N, Wu N, Park AE. Morgagni Hernia Repair: A Review. Surgical Innovation. 2018;25(4):389-399.

2. Ayane GN, Walsh M, Shifa J, Khutsafalo K. Right congenital diaphragmatic hernia associated with abnormality of the liver in adult. The Pan African Medical Journal. 2017;28(70):1-4.

3. Nasr A, Fecteau A. Foramen of Morgagni hernia: presentation and treatment. Thorac Surg Clin. 2009;19(4):463-468.

4. Kurt F, Oğuz S, Demir M, Tekin D, Suskan E. A Rare Cause of Cough in Children: Morgagni Hernia. Bozok Tıp Dergisi. 2017;7(3):99-102.

5. Al-Salem $\mathrm{AH}$. Congenital hernia of Morgagni in infants and children. J Pediatr Surg. 2007;42(9):1539-1543.

6. Atcı N, Bayaroğulları H, Doğru S, Davran R. MDBT ile tespit ettiğimiz iki yıllık diyafragmatik herni insidansımız. Düzce Tıp Fakültesi Dergisi. 2015;17(2):58-61.

7. Kuster GGR, Klıne LE, Garzo G. Diaphragmatic hernia through the foramen of Morgagni: laparoscopic repair case report. J Laparoendosc Surg 2009;2(2):93-100.

8. Altınkaya N, Parlakgümüş A, Koc Z, Ulusan Ş. Morgagni hernia: diagnosis with multidetector computed tomography and treatment. Hernia. 2010;14:277-281.

9. Loong TPF, Kocher HM. Clinical presentation and operative repair of hernia of Morgagni. Postgrad Med J. 2005;81:4144.

10. Horton JD, Hofmann LJ, Hetz SP; Presentation and management of Morgagni hernias in adults: a review of 298 cases.
Surg Endosc. 2008;22:1413-1420.

11. Başkıran A, Sağlam K, Dirican A. Laparoscopic repair in a case with Morgagni hernia. Laparosc Endosc Surg Sci. 2018;25(3):110-112.

12. Rau HG, Schardey HM, Lange V. Laparoscopic repair of a Morgagni hernia. Surg Endosc. 1994;8:1439-1442.

13. Ramachandran CS, Arora V. Laparoscopic transabdominal repair of hernia of Morgagni-Larrey. Surg Laparosc Endosc Percutan Tech. 1999;(9):358-361.

14. Pfannschmidt J, Hoffmann H, Dienemann H. Morgagni hernıa in Adults: results in 7 Patients. Scand J Surg. 2004;93(1):77-81. 